\title{
PROBLEMAS DE APRENDIZAGEM NA ALFABETIZAÇÃO: CONTRIBUIÇÕES DA PESQUISA-AÇÃO ESCOLAR
}

\author{
Cláudia Leme Ferreira Davis* \\ Maria Irene Miranda**
}

\begin{abstract}
RESUMO
Essa pesquisa tem por objetivo o processo e os resultados de uma pesquisa-ação desenvolvida em uma instituição escolar junto a alunos na fase de alfabetização e seus respectivos professores. Foi feito, de início, um diagnóstico sobre as dificuldades apresentadas pelos alunos para que, com base nele, fossem propostas ações pedagógicas diversificadas, capazes de superá-las. Foram então realizadas observações participantes e desenvolvidas atividades com os alunos indicados pelas professoras como problemas de aprendizagem: 21 crianças (16 meninos e 5 meninas) de $1^{\mathrm{a}}$ e $2^{\mathrm{a}}$ séries, todas repetentes, com faixa etária variável entre 8 e 12 anos de idade. As atividades permitiram analisar os conhecimentos disponíveis, bem como inferir as estruturas cognitivas já construídas pelos aprendizes, identificando possíveis problemas de interação com o meio social e com o próprio objeto de conhecimento. Com isso, foi possível agrupar os alunos em três níveis distintos de conhecimento, cada um deles envolvendo determinadas competências e concepções sobre a língua escrita. Esses níveis serviram de suporte para a construção de novos conhecimentos linguísticos. A intervenção aconteceu em duas salas de aula das quais faziam parte outros alunos que não aqueles diretamente envolvidos no projeto. $\mathrm{O}$ referencial piagetiano orientou a pesquisa.
\end{abstract}

Palavras-chave: Problema de aprendizagem. Alfabetização. Intervenção.

\footnotetext{
* Doutora em Psicologia Escolar e do Desenvolvimento Humano pela Universidade de São Paulo (USP). Professora titular do Departamento de Pós-graduação em Psicologia da Educação da Pontíficia Universidade Católica de São Paulo (PUC-SP) e pesquisadora sênior da Fundação Carlos Chagas.E-mail: cdavis@fcc.org.br

** Doutora em Psicologia da Educação pela Pontíficia Universidade Católica de São Paulo (PUC-SP). Professora da Faculdade de Educação da Universidade Federal de Uberlândia (UFU).E-mail: mirene@ufu.br
} 


\begin{abstract}
This research aims to present the process and the results of a research-action intervention, developed in order to improve the knowledge of students learning how to read and write and the teaching of their teachers. For the diagnosis, participant observations were accomplished and activities were proposed to students seen by the teachers as having learning problems: 21 children (16 boys and 5 girls from 8 to 12 years old) of $1^{\text {st }}$ and $2^{\text {nd }}$ grades. The activities allowed to grasp the available knowledge as well as to infer the cognitive structures already built by the children, verifying possible difficulties in interacting with the social environment and with the knowledge object (the language). Consequently, it was possible to classify the students in three different levels, each one involving certain competences and conceptions about the written language, which served as a base for constructing new knowledge about it. The intervention occurred in two classrooms, which were not composed only of students involved in the project. Piaget's theory guided the research.
\end{abstract}

Keywords: Learning problems. Teaching how to read and write. Intervention

\title{
Introdução
}

O objetivo da pesquisa desenvolvida em uma escola pública da rede municipal na cidade de Uberlândia (MG) foi analisar os efeitos de uma intervenção escolar no enfrentamento dos "problemas de aprendizagem" dos alunos durante a alfabetização, investigando, ainda, a contribuição das professoras alfabetizadoras e da pedagoga nesse processo. O interesse em desenvolver uma pesquisa de intervenção surgiu de estudo anterior, o qual revelou que crianças consideradas problemas podiam aprender mediante uma intervenção devidamente planejada, que levasse em conta seus níveis de conhecimento. Para tanto, a professora alfabetizadora deveria fazer propostas diversificadas para atender à realidade discente, um desafio para quem atua de forma a homogeneizar os alunos, tratando como igual o que é essencialmente diferente. A partir desse entendimento foi contatada uma escola pública da rede municipal de ensino e proposta uma pesquisa-ação, cuja meta estava em atuar junto aos alunos com dificuldades no processo de aquisição e desenvolvimento da leitura e da escrita e, ainda, junto aos 
professores alfabetizadores, tendo em vista suas dificuldades em avaliar os alunos e propor ações diversificadas. A escola foi muito receptiva à ideia. A diretora, a pedagoga e as professoras ficaram muito animadas e assumiram o compromisso de serem participantes no processo da pesquisa-ação.

\section{O começo do trabalho: definindo caminhos}

No início do ano letivo de 2002, a dinâmica da escola foi observada mediante acompanhamento do trabalho das professoras e da pedagoga e também participando no sentido de subsidiar, pedagogicamente, as reuniões de estudo da escola e as de pais e mestres, e oferecendo auxílio para a realização dos eventos socioculturais. Dessa forma, tornou-se possível à pesquisadora conhecer a realidade escolar e ser aceita na instituição, requisito fundamental à pesquisa-ação, na medida em que o trabalho coletivo é um de seus princípios básicos. Nesse período, em diferentes circunstâncias, foi possível inteirar-se das queixas das professoras com relação aos alunos, as quais foram registradas por meio de um questionário inicial. As respostas obtidas foram organizadas em duas categorias de análise: indisciplina e dificuldades especificas de leitura e escrita.

A preocupação com a indisciplina indicava, claramente, que as docentes consideravam a manutenção da ordem em sala de aula um requisito básico e essencial para a alfabetização dos alunos. Além disso, as posturas das professoras em face ao trabalho pedagógico variavam muito. Algumas eram muito exigentes: queriam que as crianças assimilassem rapidamente todo o conteúdo trabalhado, exigindo, para tanto, que elas se comportassem como um adulto. Outras professoras já eram permissivas: acreditando que a aprendizagem se processa de maneira espontânea, não ofereciam referências aos alunos e nem direcionavam seu trabalho, deixando-os completamente à vontade.

Agravava ainda a indisciplina o fato das atividades propostas nem sempre serem adequadas ao nível de conhecimento dos educandos. De fato, ora elas estavam aquém, ora além de suas possibilidades, causando desinteresse ou apatia que redundava, consequentemente, em desordens na sala de aula. Em outras palavras, as atividades propostas estavam muitas vezes em descompasso com a situação cognitiva e afetiva dos alunos. 
Assim, as observações mostraram que as professoras não se davam conta das características da faixa etária com que trabalhavam ao propor as atividades de alfabetização, ignorando que quando a tarefa "tem caráter lúdico e corresponde ao nível de desenvolvimento, a criança é, habitualmente, disciplinada, mesmo porque 'disciplina' é apenas empenho na realização de uma proposta” (LIMA, 2000, p. 113). A partir dessas considerações, pensou-se que o problema da indisciplina seria amenizado por meio de atividades mais condizentes às realidades dos alunos, constituindo esse um primeiro objetivo da pesquisa.

Em relação às dificuldades especificas de leitura e de escrita, a observação mostrou que 'saber ler e escrever' era o critério que distinguia os "bons" dos "maus" alunos. Como o domínio do código, em seu sentido restrito (codificação e decodificação) era a meta almejada pelas professoras, as atividades pedagógicas centravam-se nesses conteúdos. Havia, dessa maneira, uma discrepância entre o nível de exigência das atividades propostas em sala de aula e o nível de desenvolvimento dos alunos, algo que poderia explicar os resultados insatisfatórios que a escola relatava alcançar. De fato, como bem explicita Lima (2000, p. 121), “[ [..] é perfeitamente provável que o 'fracasso da aprendizagem' decorra da inadequação entre o nível de desenvolvimento mental da criança e o nível da complexidade operacional da tarefa (lição) proposta, pois o natural do processo vital é aprender ('todo esquema tende assimilar todo o objeto')".

À luz da perspectiva construtivista, o planejamento das atividades deve considerar a relação entre os níveis de desenvolvimento das crianças e a complexidade das tarefas que lhes são propostas. Com isso, delineouse um segundo objetivo da pesquisa: identificar os equívocos cometidos e tentar superá-los, levando as professoras a repensarem sua ação. Isso exigia que fossem analisadas as causas atribuídas às dificuldades dos alunos. Verificou-se que, segundo as concepções das professoras, os problemas em alfabetização correspondiam a fatores extraescolares: as condições socioeconômicas, os problemas familiares e alguma disfunção orgânica eram os determinantes da situação de aprendizagem do aluno. Em consonância com os resultados de um estudo realizado anteriormente (Miranda, 2000), em nenhum momento os fatores escolares (relação professor-aluno, a metodologia de ensino, os recursos didáticos etc.) 
apareciam como causas das eventuais dificuldades de aprendizagem dos alunos. Confirmando essa perspectiva reducionista, as docentes pensavam que a solução para tais problemas estava situada fora da escola, uma vez que consideravam já estarem fazendo o que podiam.

Nesse sentido, acreditavam que somente um profissional externo, com competências diferenciadas, poderia sanar as dificuldades que encontravam no processo de ensino e aprendizagem. Efetivamente, não se percebiam como construtores ou produtores de alternativas de ação, de novos saberes. Na base dessa concepção equivocada da função docente aparecia, mais uma vez, a cultura pedagógica que acreditava existir propostas prontas, feitas para serem aplicadas aos alunos. Superar esse equívoco foi outro objetivo da pesquisa. De fato, sem o envolvimento dos docentes não há como alcançar êxito no trabalho coletivo, correndose o risco de estabelecer um distanciamento acadêmico entre aqueles que supostamente sabem (os pesquisadores) e aqueles que, passivamente, aguardam uma solução (os professores).

O envolvimento das professoras, como participantes da pesquisaação, foi se dando gradativamente e não ocorreu da mesma forma com todo o grupo: umas se envolveram mais e outras menos, porém todas foram respeitadas em suas decisões de participarem ou não da pesquisa, visto que foram alertadas da necessidade de estudo e de construção coletiva de propostas de intervenção. A definição das professoras participantes decorreu, portanto, da realização de um diagnóstico psicopedagógico dos alunos, que requeria, dada a complexidade dos casos estudados, discussões e trabalho em grupo. Esse diagnóstico cumpriu, assim, uma outra função: mostrar às docentes que a pesquisa-ação só seria bem sucedida se elas estivessem de fato nela envolvidas.

\section{Diagnóstico psicopedagógico: realização e análise}

Para o diagnóstico foram realizadas observações participantes e desenvolvidas atividades com os alunos indicados pelas professoras como problemas de aprendizagem. Eram vinte e uma crianças (16 meninos e 5 meninas) de $1^{\mathrm{a}}$ e $2^{\mathrm{a}}$ séries, todas repetentes, com faixa etária variável entre 8 e 12 anos. Os alunos eram crianças sofridas. Suas histórias de vida 
revelavam sacrifícios da família, que repercutiam sobre elas. Os pais ou responsáveis saíam, em geral, muito cedo para trabalhar, retornando a casa somente tarde da noite. Nesse período, as crianças ficavam sozinhas, aos cuidados de um irmão um pouco mais velho ou de um vizinho que a elas se dedicava quando era possível. A maior parte do tempo as crianças ficavam na rua, sem horário para se alimentar, banhar-se ou preparar-se para ir à escola. $\mathrm{O}$ resultado era o esperado: elas não faziam as tarefas escolares e não estudavam fora do horário de aula. Ficar na rua implicava, ainda, maior exposição aos mais diversos exemplos de condutas, sem orientação sobre como agir, mas sendo sempre punido pela atividade tida pelos pais ou pares como ilícita. O bairro no qual viviam e onde a escola se localizava era considerado violento, com incidências de tráfico de drogas e roubo.

Algumas crianças não apresentavam hábitos de higiene desenvolvidos: frequentavam a escola com roupas e sapatos sujos, sem tomar banho, às vezes, até com um cheiro forte no corpo e os cabelos despenteados. Diante dessa realidade, foi sugerido um trabalho de conscientização junto à família, informando a importância dos cuidados com o corpo, sobretudo para crianças em processo de construção de identidades e valores. Para tanto, seria necessário que a escola conseguisse trazer os pais para participarem de forma mais efetiva e ativa da vida acadêmica de seus filhos. Poderiam ser oferecidas palestras, cursos diversos, eventos esportivos e culturais, de acordo com o interesse da comunidade. Seria importante que essas ações fossem constantes e fizessem parte do planejamento da escola, na medida em que, de outra forma, não dariam os resultados esperados: mudanças de hábitos. Realmente, alterar rotinas e hábitos requer processos de reeducação, com ações contínuas e não esporádicas.

Para conhecer um pouco mais os alunos foram propostas atividades por meio das quais foi possível analisar os conhecimentos disponíveis, ou seja, as estruturas cognitivas já construídas pelos aprendizes, verificando possíveis dificuldades de interação com o meio físico e social e com o próprio objeto de conhecimento. As tarefas propostas tinham por objetivo desafiar o pensamento dos alunos, favorecendo a compreensão sobre como construíam argumentos diante de um determinado conflito. A meta era, portanto, analisar os processos psicológicos em andamento e não apenas os já elaborados; potencializar as possibilidades do aprender e não estabelecer rótulos ou estigmas. 
Sem deter o aluno em uma situação experimental estruturada e interferindo com questionamentos para provocar suas respostas, cada um deles fez as seguintes atividades: desenho livre; escrita e leitura do nome próprio; escrita de palavras e números; escrita de frases; leitura de palavras e frases. Adicionalmente, a observação do material escolar, as conversas informais e a observação dos alunos em situações de jogos foram também objeto de análise. Com isso, foi possível agrupar os alunos em três níveis distintos de conhecimento: nível I, nível II, nível III. Cada nível envolvia determinadas competências e concepções sobre a língua escrita, servindo de suporte para a construção de novos conhecimentos linguísticos. Nesse momento, o referencial teórico piagetiano foi fundamental, uma vez que contribuiu para propiciar um novo olhar acerca da criança e de suas produções. De acordo com esse paradigma, ao entrar na escola, os alunos apresentam uma inteligência em processo, cujo desenvolvimento é marcado por diferenças que impedem almejar, de todos, um único e mesmo desempenho ou as mesmas noções em relação ao funcionamento da língua.

As respostas dos alunos às atividades do diagnóstico confirmaram as premissas acima. Os desenhos livres, no nível I de conhecimento, tinham contornos bem definidos, sem definição de detalhes. Eram estereotipados (casa, árvore, sol) com temas espontâneos, sem intenção à priori. Cópias do desenho de um amigo ou de um livro eram comuns. No nível II de conhecimento os alunos produziam desenhos com contornos mais definidos, com melhor uso de detalhes. Finalmente, no nível III de conhecimento, os desenhos adquiriam formas definidas, riqueza de detalhes e maior definição no traçado e no colorido. Supunha-se, como observado, uma evolução conceitual do nível I para o Nível III, quando as interações com os objetos de conhecimento adquirem maior complexidade operatória. Os desenhos revelaram este progresso gradativo: avanços nas experiências operatórias implicavam desenhos mais definidos, com traçados qualitativamente distintos e uma melhor captação do objeto reproduzido.

$\mathrm{Na}$ escrita e leitura do nome próprio, os alunos do nível I identificavam os nomes em diferentes contextos (crachá, ficha de frases); liam de maneira global, sem relacionar as partes, fazendo corresponder à emissão sonora e o segmento gráfico. Memorizaram a escrita do nome, porém não era raro algum aluno omitir letras ou variar a segmentação 
gráfica. No nível II liam e escreviam o pré-nome corretamente e tentavam escrever o nome completo, porém com omissão e variação das letras. A leitura deixava de ser global, apresentando correspondência entre as partes, indício da incipiente relação gráfica - fonológica na escrita. No nível III, o domínio na escrita e na leitura do nome próprio ficava patente, com as crianças passando a operar conforme os princípios alfabéticos. A análise revelou que enquanto o aluno do nível I escrevia o pré-nome utilizando as letras (convencionais ou não) de forma aleatória, os alunos do nível II já dispunham de alguns critérios grafo-fonológicos para escrita, e os do nível III escreviam o nome de forma convencional, às vezes até mesmo por completo, mesmo quando havia complexidades ortográficas. Na leitura, os alunos de todos os níveis identificavam o nome, porém somente os do nível I admitiam a possibilidade de haver um outro significado para essa grafia.

A natureza evolutiva da conservação da relação gráfica e fonológica fica clara nessas situações: se, no princípio, as crianças acreditam que uma única sequência de letras pode ter significados distintos, na medida em que vão desenvolvendo sua consciência grafo-fonológica, há uma mudança de concepção e de hipótese conceitual, passando-se, consequentemente, a não mais admitir significados distintos para uma mesma sequência de letras. Os alunos do nível II e III liam em seus crachás ou fichas de identificação fornecidas pela professora somente o nome próprio e não aceitavam que aquela sequência de letras pudesse ter outro significado. Nesse sentido, o conhecimento com relação ao nome próprio é tido como mais amplo que apenas o domínio da leitura e da escrita convencional, uma vez que compreende diferentes propriedades do sistema de escrita: letras maiúsculas e minúsculas, sequência de letras com seus respectivos sons, sílabas simples e complexas.

$\mathrm{Na}$ escrita de palavras e números, os alunos do nível I usavam as letras de forma aleatória, sem categorização gráfica (maiúscula, minúscula, imprensa, cursiva), mas com maior facilidade na letra de imprensa. O conhecimento do alfabeto era precário e não havia conservação gráfica e sonora. Confundiam letras e sílabas. No nível II, o uso de letras oscilava da forma aleatória ao uso de algum critério, que poderia ser, principalmente, as letras e sílabas trabalhadas pela professora. Neste nível, havia um melhor domínio da escrita cursiva e das categorias gráficas, muito embora 
letras e sílabas ainda fossem confundidas. Os alunos do nível III não tinham dificuldades para escrever palavras com sílabas simples (consoante e vogal) e nem confundiam letras e sílabas: faziam uso de categorização gráfica, não misturando, portanto, letras maiúsculas e minúsculas ou letras de imprensa e cursivas. Suas dificuldades estavam nas sílabas complexas (consoante, consoante, vogal - como TRA - ou consoante, consoante, vogal, consoante, como PLAN), nas escritas com variações ortográficas ${ }^{1}$ (por exemplo, escrever CAZA para CASA ou PALIASO para PALHAÇO) e na falta de habilidades textuais (produção escrita com coerência, coesão e sequência de ideias).

A análise da escrita de palavras e números revelou que, no nível I, o conhecimento disponível sobre os aspectos gráficos não garantia a compreensão da escrita como sistema de representação, tanto que o uso de letras na escrita e o significado atribuído às palavras nas tentativas de leitura eram ambos aleatórios Neste nível, o pensamento é sincrético, justificando as generalizações antecipadas que não consideram os elementos da língua em sua totalidade e em suas dimensões. $\mathrm{O}$ avanço conceitual ocorreu mediante o confronto dos elementos linguísticos com os esquemas mentais disponíveis que para possibilitar a incorporação de novos conceitos e, consequentemente, de novas sínteses mentais, foram transformados, transformando, ao mesmo tempo, o agir e o pensar da criança em relação à escrita. Assim, em suas tentativas de produção escrita, a criança ia superando o uso simultâneo de mais de um tipo de letra e passava a construir as categorias gráficas (maiúscula, minúscula, imprensa, cursiva). Compreender que disposições gráficas distintas podem ter significados idênticos é uma atividade cognitiva bastante complexa.

As características conceituais no nível II de conhecimento indicavam certa consciência grafo-fonológica que, se permitia empregar algum critério na produção escrita, era, porém, insuficiente para levar à compreensão das irregularidades que caracterizam as relações entre sons e letras. Nesse sentido, quando o aluno verificava que uma mesma letra

\footnotetext{
1 Variações ortográficas são tentativas de organização da escrita de acordo com as convenções ortográficas, não podem, portanto, ser consideradas erros, pois sintetizam um esforço de compreensão, uma hipótese acerca do funcionamento da língua. Para maior aprofundamento sobre o termo ver Alvarenga (1995).
} 
podia ter diferentes sons (por exemplo, o S no início da palavra - sapo; e o S intervocálico - mesa) um conflito cognitivo se instalava. Para solucionálo, ou seja, para reagir às perturbações por meio da (re)coordenação dos esquemas mentais, era necessário que os alunos enfrentassem situações que abordavam as complexidades da relação grafema - fonema e compreendessem, assim, o princípio acrofônico que regula o sistema alfabético.

No nível III de conhecimento predominava uma maior compreensão acerca do sistema linguístico, permanecendo comuns, no entanto, os conflitos de natureza ortográfica. As produções escritas eram marcadas por organizações lógicas e esforço de compreensão. Nessa medida, quando não correspondiam ao convencional, configuravam os chamados 'erros construtivos', ou seja, produzidos na tentativa de regularizar a escrita, utilizando hipóteses acerca do funcionamento da língua. Priorizar a escrita ortográfica implica, nesses casos, desconsiderar todo o esforço da criança, esquecendo que a impossibilidade de variação ortográfica decorre do caráter normativo, regular e arbitrário das convenções da língua escrita. A apropriação ativa das regras ortográficas envolve compreensão analítica, uma atividade mental contrária aos procedimentos tradicionais que, quase sempre, fundamentam-se na mera transmissão de conhecimentos.

Em qualquer dos três níveis estabelecidos, seria fundamental que a criança vivenciasse atos de leitura e de escrita, confrontasse textos, emitisse opiniões, formulasse perguntas e oferecesse respostas. Como objeto de conhecimento, a língua escrita está presente no cotidiano de forma plena, criativa e não limitada a métodos ou normas padronizadas. $\mathrm{Na}$ abordagem adotada, não são as propostas metodológicas que constroem a aprendizagem e, sim, a interação com o objeto. Nessa perspectiva, o mediador da aprendizagem é alguém que tem disposição tanto para seguir a lógica adotada pelo aluno como para atuar na diversidade, propondo atividades que atendam aos diferentes níveis de conhecimento.

$\mathrm{Na}$ escrita de frases com o nome próprio, a criança do nível I atribuía ao nome, ou parte dele, outras palavras da frase. Comumente, não segmentava as palavras, o que era observado também em frases sem a escrita do nome. Na produção escrita por meio de gravuras era o caráter descritivo que predominava, com elaborações curtas e simples (por exemplo: para a 
gravura de um pato na lagoa escrevia: "O pato está na lagoa" ou "O pato é amarelo"). Já a criança do nível II não atribuía outros significados ao seu nome, ou seja, quando escrevia o nome próprio não mais aceitava ler outra coisa que não fosse o nome, reafirmando, assim, o início de critério grafo-fonológico. Havia tentativas de segmentação das palavras da frase. Da mesma forma que no nível anterior, na produção a partir de imagem, predominava o caráter descritivo, com frases curtas e simples. O mesmo ocorria para frases sem imagem: havia uma preocupação em escrever utilizando somente palavras conhecidas, o que limitava a possibilidade de produção. No nível III, ao escrever o nome, a criança não lhe atribuía outro significado. A produção escrita tinha critério fonológico, semântico e sintático, não se fazendo mais uso aleatório de letras. Casos de fusão ou cisão (escrever frases sem a segmentação convencional das palavras) ainda eram observados. As frases produzidas eram curtas e simples. Quando produzidas a partir de uma imagem, o caráter descritivo adquiria saliência.

Ao analisar a escrita das frases as características de desenvolvimento verificadas em outras atividades foram confirmadas. Assim, no nível I, as letras eram utilizadas de forma aleatória, enquanto no nível II já se podia notar um início da fonetização da escrita: as crianças tinham descoberto que a escrita representa a fala, mas ainda não compreendiam que escrever não significa transcrever a fala. Sendo assim, em suas tentativas de escrita, elas tentavam reproduzir a pronúncia das palavras, o que resultava, quase sempre, em transgressão das normas ortográficas. Mesmo as crianças do nível III, que apresentavam consciência fonográfica mais evoluída, utilizavam a fala, em alguns momentos, como referência para a escrita, de modo que suas produções continham variações ortográficas, principalmente em relação às sílabas complexas ou irregulares da língua escrita. Quando o aprendiz busca uma regularidade para os sons da fala, ele levanta hipóteses que precisam ser confrontadas por meio de situações que abordem a complexidade do mundo da escrita, confirmando-as ou refutando-as. É, ainda, dessa forma - confrontando suas produções com o convencional e vivenciando atos de leitura - que se pode ver a segmentação de palavras na frase como uma das características do sistema de escrita.

A leitura favorece, também, a competência para a produção escrita, superando as limitações enfrentadas para elaborar frases ou textos. Desse 
modo, na atividade de leitura, as crianças do nível I faziam corresponder emissão sonora e sequência do texto, podendo atribuir-lhe significados aleatórios (quando não contavam com o apoio de imagem) ou realizavam uma "leitura" descritiva, que propunha um contexto para a leitura (se o texto se fazia acompanhar de uma figura). Para o nível II, o caráter descritivo também prevalecia, porém já se notava iniciativas de extrapolar o que a imagem sugeria. Ao ler, as crianças deste nível faziam corresponder à emissão sonora e ao segmento gráfico. Quando o texto não tinha imagem, tentavam ler com base nos conhecimentos linguísticos que dispunham. No nível III a leitura podia se dar de maneira independente da imagem, embora as crianças buscassem estabelecer relações entre a figura e o texto. $\mathrm{Na}$ leitura sem imagem utilizavam os conhecimentos disponíveis para ler o texto, encontrando dificuldades nas sílabas complexas, na pontuação e, principalmente, na interpretação.

A partir destes dados foi possível verificar que, de acordo com o nível de conhecimento, as crianças apresentavam distintas formas de leitura. Para os textos seguidos de imagem, as do nível I propunham a reprodução de seu significado convencional, ou seja, a escrita consistia em representar o nome do desenho. Quando o texto não tinha nenhuma imagem, a criança atribuía-lhe um significado aleatório ou negava-se a ler. A relação entre escrita e imagem era mantida no nível II, mas se buscava no texto indicadores que sustentassem as hipóteses tecidas. Considerar as propriedades do texto escrito (letra inicial, letra do nome etc.) foi tido como indicação de avanço significativo, pois a criança tenta ler, inclusive, com base nos conhecimentos que detém sobre a língua escrita. Isso também ocorria para as crianças do nível III, que não aceitavam somente a imagem como referência para a leitura. Os conceitos construídos acerca do funcionamento do sistema da língua embasavam as tentativas de leitura e eram, quase sempre, bem sucedidas, principalmente quando o texto não oferecia palavras muito complexas. Deve-se considerar, porém, que a leitura não é somente decodificação; a compreensão é nela fundamental, na medida em que favorece a aprendizagem e amplia o conhecimento do código escrito.

Nas situações de jogos, as crianças do nível I tinham dificuldades em organizar uma estratégia e facilmente desconsideravam suas regras, 
principalmente em benefício próprio, pois não reagiam bem diante da frustração de perder o jogo. Durante a atividade (e também em outros momentos) falavam de vários assuntos ao mesmo tempo e dispunhamse menos a ouvir, revelando pouca concentração. Comportamentos egocêntricos, caracterizados pela dificuldade de cooperação com seus pares, foram encontrados. Cada uma queria jogar a sua maneira. Raramente as crianças situadas nesse nível mantinham o material escolar organizado e copiavam do quadro com grande dificuldade. As crianças do nível II revelavam dificuldades em organizar estratégias e facilmente desconsideravam as regras do jogo. Assim como no nível anterior, não havia cooperação e também falavam mais do que ouviam, abordando diferentes assuntos ao mesmo tempo. Manifestavam comportamentos egocêntricos, $\mathrm{o}$ que dificultava considerar a perspectiva do outro no jogo. Perder era quase sempre muito angustiante. Em relação ao material escolar, eram pouco organizadas e podia-se notar que tinham dificuldade em copiar do quadro, razão que levava as lições, em seus cadernos, a serem incompletas. No nível III, as crianças estavam atentas às regras do jogo, muito embora tentassem modificá-las fazendo uso de novas estratégias. Interagiam melhor com os colegas, o que marcava o início da descentralização, isto implicava admitir a perspectiva do outro para o desenvolvimento do jogo. O material escolar encontrava-se mais organizado, mas cadernos incompletos, com cópias incorretas e mal cuidadas, eram ainda encontrados.

As situações de jogos sempre oferecem momentos ricos de interação e compreensão do universo infantil, de modo que por seu intermédio foi possível inferir uma inteligência em processo, uma relação entre a estrutura cognitiva e o desenvolvimento do jogo. As crianças que manifestavam características do pensamento egocêntrico apresentavam progressiva descentralização do nível I para o nível III de conhecimento, caminhando para o pensamento operatório. Isto significa que elas foram gradativamente ampliando suas perspectivas, desenvolvendo a reciprocidade interpessoal, a reversibilidade de pensamento e a autonomia moral e intelectual. Se o brincar é fundamental para a adaptação intelectual e afetiva da criança, possibilitando o surgimento de uma inteligência representativa do real, as práticas de intervenção precisavam priorizar as atividades lúdicas, não para substituir as atividades escolares, mas para torná-las mais compreensíveis. 
Em nenhum momento se considerou o brincar como uma perda de tempo. O lúdico foi tido como mais uma opção para a prática docente, procurando-se levar o professor a usar critérios para selecionar determinadas atividades. De fato, não é qualquer situação que vai favorecer a construção do conhecimento. Para que desencadeie conflitos e favoreça a organização do pensamento, a atividade deve ser coerente com o nível de desenvolvimento da criança, despertando seu interesse e desafiando a sua inteligência.

Por meio de conversas informais, foi observada, do nível I para o III, uma evolução psicogenética tanto no discurso como nas atitudes dos alunos, assim como uma progressiva socialização de seu pensamento: as ações tornaram-se mais coordenadas e planejadas; havia uma maior aceitação do ponto de vista do outro. Esse processo evolutivo social, cognitivo e afetivo ocorre à medida que a criança estabelece relações com o mundo, amplia seus conceitos e perspectivas. Em relação ao uso e manuseio do material escolar (algo que se aprende), quase nunca foram encontradas orientações sobre como com ele lidar ou sobre como fazer os registros no caderno, se copiado do quadro ou de livros. O uso convencional era aprendido gradativamente, assim como a solução para os casos de espaçamento entre palavras, omissão de letra e falta de legibilidade, conforme revelaram as crianças do nível I, II e III. No entanto, é importante considerar que fazer uma cópia pode ser um desafio, envolve habilidades de coordenação visomotora, noção espacial e sequencial, percepção e discriminação visual.

Muitos outros fatores interferem nas possibilidades de êxito dessa atividade: tipo de letra utilizado pelo professor, ritmo exigido para conclusão da atividade, volume de escrita a ser copiada. O professor poderia favorecer o desenvolvimento do aluno se oferecesse orientações paralelas e contínuas, de acordo com as necessidades observadas nos cadernos. Por exemplo, colocar marcas no quadro e no caderno para indicar o espaço para cópia, o início e o fim, dentre outras.

Por fim, conversas informais com os pais ou responsáveis contribuíram também para elucidar o perfil do aluno e compreender algumas de suas dificuldades na escrita. A partir da análise do diagnóstico, tornouse possível propor uma intervenção em sala de aula, cujo desenvolvimento será apresentado a seguir. 


\section{A intervenção psicopedagógica: planejamento, desenvolvimento e avaliação}

Para estudar a situação dos alunos e planejar a intervenção, foram realizadas reuniões semanais, que se constituíam também em espaços para discussões, para troca de ideias, para compartilhar problemas, dúvidas e ansiedades. Considerando a necessidade de os professores se envolverem no trabalho, a intervenção aconteceu em duas salas de aula, sendo uma de $1^{\mathrm{a}}$ e outra de $2^{\mathrm{a}}$ série, que não eram compostas somente de alunos diretamente envolvidos no projeto. Esse cuidado foi para evitar que essas salas de aula acabassem caracterizadas como salas especiais e, muito menos, rotuladas de turmas homogêneas. Uma classe de alfabetização é, por natureza, heterogênea, uma vez que as histórias de vida e as experiências escolares são diversificadas. Algumas crianças sabem algumas coisas, outras sabem outras, alguns são repetentes, outros são novatos.

Do ponto de vista interacionista, essa diversidade é um aspecto positivo, pois se entende que a aprendizagem seja um processo que envolve estruturas e esquemas mentais, cuja construção ocorre por meio de mecanismos internos (a partir de conflitos que excitam o pensamento) e por mecanismos externos (a partir das interações com o meio). Nessa perspectiva, a relação entre alunos de níveis diferenciados de pensamento é considerada fator de desenvolvimento. Baseando-se na premissa piagetiana de que diferentes níveis de desenvolvimento do pensamento necessitam de mediações distintas, o planejamento da intervenção partiu das características das crianças. Como não é possível padronizar a aprendizagem, é preciso que o professor entenda que a ela não corresponde inteiramente aquilo que foi ensinado e, ainda, que os alunos não aprendem todos ao mesmo tempo e no mesmo ritmo. Sendo assim, se o processo de aprender não pode ser controlado, ele deve, não obstante, ser acompanhado, segundo estilo e interesse de cada aprendiz.

Apartirdesses princípios, fez-se necessáriouma reflexãopermanente acerca das ações desenvolvidas, (re)planejando-as com base na realidade dos alunos, levando-os a aprender, a eliminar obstáculos e dificuldades que sempre se colocam à aquisição do conhecimento. Nas palavras de Piaget, "[...] é preciso que os professores aceitem a imensa responsabilidade das 
orientações individuais e compreendam suficientemente a complexidade dos problemas para assegurar as colaborações úteis" (1969, p. 129). A atuação do mediador precisa, portanto, envolver observação e interpretação das diversas atitudes e comportamentos dos alunos, liberando-se das amarras da normatização.

Tendo em vista os níveis de conhecimento identificados no diagnóstico, foram propostas situações favoráveis ao avanço dos alunos, as quais não correspondiam a metodologias, técnicas ou procedimentos de ensino pré-definidos. Se a inteligência é um sistema aberto à pluralidade de combinações não previsíveis, a intervenção "consiste em criar situações tais que o aluno é chamado a agir mentalmente, de uma maneira que seja estruturante, integrando suas ações num sistema de coordenação e de composição operatórias" (VINH-BANG, 1990, p. 9). As atividades propostas tinham o objetivo de desafiar o aluno mediante o contato com o objeto de conhecimento, causando, assim, um estado de desequilíbrio, no sentido piagetiano do termo. As ações eram diversificadas, construtivas e dialógicas, sendo comum a realização de tarefas diferentes, em grupo ou individualmente. $\mathrm{O}$ trabalho conjunto e a utilização de jogos e outras atividades lúdicas, antes consideradas motivo de desordem na sala, tornaram-se rotineiros. Todas as tarefas propostas requeriam esforço de compreensão, pensamento autônomo, iniciativa, capacidade de análise, trabalho coletivo, clima de cooperação, interação.

$\mathrm{Na}$ aprendizagem da leitura e escrita, o texto foi considerado como unidade básica da intervenção. Dessa forma, os conteúdos eram trabalhos a partir de textos que conferiam significado e sentido à língua escrita. A multiplicidade e diversidade de informações dos diferentes portadores de texto contribuíram, também, para o domínio dessa área do conhecimento. O trabalho com textos não significou deixar de abordar as partes que o constituíam, quais sejam, as frases, palavras, sílabas, letras. O aprendizado da língua escrita processa-se na diversidade, mediante diferenciações, integrações e reconhecimento das restrições e regularidades combinatórias dos elementos constituintes do sistema linguístico.

Os alunos participavam bem de todas as atividades propostas, com envolvimento e interesse. Suas produções eram sempre significativas, pois revelavam seus conhecimentos. Suas perguntas e respostas eram sempre 
validadas pela atenção do mediador, que buscava compreender o que lhe era colocado pelos alunos. As dúvidas e equívocos eram tidas como indícios que apontavam se havia necessidade de mediação para fazer os mecanismos de processamento operatório avançar na aprendizagem. No decorrer do processo, os alunos habituaram-se à dinâmica da intervenção e se envolviam com as propostas; participavam ativamente das reuniões com companheiros do mesmo nível de conhecimento, assim como de atividades com colegas de níveis diferentes, favorecendo a troca entre pares e levando uma criança a atuar como mediadora para outra. Esse procedimento era muito interessante por possibilitar a interação dos alunos com outros que não eram da mesma sala e, ainda, com outros professores.

Nas reuniões semanais da pesquisa eram realizadas avaliações processuais, discutindo as situações dos alunos e as ações (re)planejadas. Para melhor acompanhamento, o diagnóstico processual passou a ser adotado como mecanismo para conhecer o desenvolvimento das crianças, os avanços nos níveis de conhecimento e, consequentemente, a eficácia da intervenção. Dessa maneira, as mesmas atividades do diagnóstico inicial foram retomadas e analisadas, revelando uma evolução conceitual: alguns alunos já estavam alfabetizados, mesmo apresentando dúvidas com relação à interpretação e à produção escrita. Esse dado implicou, por sua vez, uma mudança na concepção das professoras: se antes da intervenção eram considerados alfabetizados somente os alunos que sabiam ler e escrever sem cometer erros, depois da intervenção essa classificação ficou mais flexível, envolvendo também as crianças que escreviam de forma alfabética não ortográfica.

Havia sido estabelecido um entendimento de que o conhecimento letrado se desenvolve durante a escolaridade da criança, que vai paulatinamente compondo textos mais complexos com um número cada vez menor de erro. Os resultados obtidos animaram as professoras, levandoas a acreditar mais na capacidade dos alunos: discutiam, explicavam e defendiam as mudanças encontradas em seus alunos, até mesmo em eventos científicos, nos quais apresentaram o projeto. Essa oportunidade de socialização das experiências vividas teve um impacto positivo no grupo: a interlocução com outros alfabetizadores fez com que as professoras se sentissem respeitadas e, sobretudo, produtoras de saberes. Em termos 
piagetianos, houve um processo de "tomada de consciência", quando as professoras transformaram os seus saberes a partir da (re)construção de suas ações.

Essas transformações tiveram também impacto na prática avaliativa, uma vez que foram abolidas atividades com o fim específico de avaliação quantitativa, como as tradicionais provas. As discussões sobre os alunos nos encontros semanais, assim como as atividades do cotidiano, revelavam o quanto cada um deles havia progredido, bem como o que ainda precisava melhorar e em que necessitava de mediação. Em sendo assim, a avaliação somativa e classificatória deixou de ser pertinente à intervenção, uma vez que uma nota ou um conceito não significava parâmetro para a aprendizagem e competência dos alunos. De fato, é possível obter notas para aprovação sem que se conte com conhecimentos suficientes, caso em que se aprende a dar uma resposta correta mesmo na ausência de avanços conceituais.

A despeito de a avaliação ter sido uma questão polêmica, ficou estabelecido, nas salas do projeto, que se valorizaria mais o processo do que o produto, que o envolvimento dos alunos nas atividades, sua assiduidade e iniciativa seriam consideradas. As provas não foram abolidas, porém eram elaboradas em consonância com as tarefas cotidianas. Podiam ser realizadas mediantes consultas, pois as respostas demandavam elaboração e não memorização. A prova não precisava ser concluída no mesmo dia, se houvesse necessidade poderia ser finalizada na aula seguinte. Essas medidas, embora simples, tiveram impacto positivo. $O$ aluno, sem se sentir pressionado pelo tempo, ficava mais seguro e tranquilo. $\mathrm{O}$ espírito da avaliação mudou; seu objetivo passou a ser o de indicar o que e como o aluno aprendeu, sobre como o professor ensinou e sobre o que e como deveria passar a ensinar.

Ao final da intervenção foi realizado o diagnóstico final, cuja análise revelou novo avanço conceitual dos alunos. Os resultados desse diagnóstico, acrescidos das observações processuais, serviram para avaliar a pertinência das ações de intervenção. Eles indicaram um avanço nos níveis de conhecimento caracterizado por evoluções da consciência metalinguística, de modo que os alunos construíram um conjunto de habilidades favoráveis à reflexão sobre a linguagem, sua natureza, estrutura e funções. Apontou, também, uma "tomada de consciência", no sentido piagetiano, por parte 
dos alunos, que foram se apropriando, progressivamente, dos mecanismos de funcionamento da língua escrita, assim como das formas de ação sobre esse objeto. Becker (2003, p. 29) postula que:

podemos dizer que o sujeito vai dando-se conta, por força de sua crescente capacidade representativa, de como age, tornando-se capaz de reproduzir sua ação corrigindo seus rumos, eliminando trajetos desnecessários ou criando trajetos novos, dirigindo-a para novos objetivos, etc.

Em relação à indisciplina, foram observados avanços no comportamento discente, uma vez que, segundo depoimento das professoras e constatações empíricas em sala de aula, as crianças estavam mais participativas, trabalhavam melhor em grupo, estavam mais seguras e concentradas, apresentavam mais iniciativa. Pode-se considerar que essas mudanças foram desencadeadas pela diversidade das atividades propostas, conforme o nível e o interesse das crianças. Quanto à promoção, dos vinte e um alunos do projeto, todos repetentes, dezoito foram aprovados para a série seguinte e três ficaram retidos. Não obstante, mesmo esses últimos alunos que não foram aprovados apresentaram progressos significativos, de modo que não se pode falar em fracasso escolar. Todas as crianças, independentemente da promoção, percorreram vários caminhos rumo à construção do conhecimento, assim como revelaram maior capacidade de interação e compreensão das experiências cotidianas. Novas concepções sobre a leitura e a escrita foram alcançadas.

Romper com os paradigmas tradicionais de ensino e redimensionar as práticas pedagógicas não foi tarefa fácil, exigindo reflexões constantes acerca das ações solicitadas aos alunos. Dessa forma, os exercícios de memorização foram substituídos por propostas desafiadoras, as atividades lúdicas tornaram-se mais constantes, o trabalho de grupo passou a ser sistemático. A relação professor - aluno estava mais aberta e dialógica e a própria configuração da sala de aula mudou: as crianças não ficavam mais somente enfileiradas, havia movimento, participação, elas se comunicavam e interagiam entre si. Como já foi dito, essas mudanças de hábitos e posturas foram gradativas. 
Os saberes que as professoras possuíam e transmitiam no trabalho cotidiano constituíram o ponto de partida e foram reconstruídos no exercício da pesquisa e da ação e na análise processual das propostas de intervenção. Os resultados geravam novas aprendizagens para todos os participantes do estudo, pois na criação de disponibilidade para refletir, aprende-se, inclusive, com os próprios erros. Mesmo que concepções empiristas ou aprioristas não tenham sido totalmente superadas, o grupo envolvido com a pesquisa avançou na compreensão do significado de um projeto coletivo, concebendo o processo de ensino e aprendizagem de forma qualitativamente diferente. Se antes as dificuldades desse processo eram vistas como decorrentes do aluno e de sua família, ao final da intervenção elas eram atribuídas a diversos fatores, entre eles, inclusive, a competência do professor e de sua metodologia de ensino.

Pode-se afirmar que o projeto favoreceu o surgimento de novas bases para a ação pedagógica. As professoras tentavam trabalhar a partir dos níveis dos alunos, de sua realidade cognitiva e de sua capacidade de ação sobre os objetos de conhecimento. Sendo assim, por meio da intervenção constatou-se que os alunos não apresentavam deficit e que tinham, sim, competência para aprender. Essa afirmação chamou a atenção da escola para a necessidade dela se abrir para a diversidade, entendendo que quando o acesso ao conhecimento elaborado é negado, nega-se, no mesmo movimento, a oportunidade de participar de outros espaços sociais. Nessas condições, a prática pedagógica configura-se como uma prática de exclusão que precisa ser gradativamente substituída, na escola, pela certeza de que é seu papel oferecer situações favoráveis à aprendizagem, um direito inalienável de qualquer sujeito.

\section{Considerações finais: limites e possibilidades da pesquisa-ação escolar}

Os resultados do trabalho desenvolvido revelaram que um projeto de intervenção escolar pode contribuir para amenizar a evasão e a repetência ao apresentar propostas de enfrentamento dos chamados "problemas de aprendizagem". No entanto, o encaminhamento das ações mostrou-se bastante complexo e problemático, uma vez que os princípios 
de coletividade e cooperação defendidos na pesquisa-ação nem sempre estavam presentes na estrutura organizacional e pedagógica da escola. Da mesma forma, não havia o hábito de refletir sobre esses aspectos, o que dificultava as possibilidades de modificação da realidade. A expectativa de transformação que todo projeto de pesquisa-ação alimenta precisou ser gradativamente substituída pela consciência de que as inovações não ocorriam de forma radical ou totalmente planejada. Era necessário aprender a lidar com o inesperado e com o desconhecido. Nesse sentido, afirma Thiollent (1994, p. 95):

Em todas as circunstâncias, os pesquisadores não podem aplicar uma norma de ação preestabelecida e devem ficar atentos à negociação do que é realmente transformável em função das formas de poder, do grau de participação dos interessados e da especificidade das formas de ação.

Sendo assim, não existem formas pré-definidas de desenvolver o trabalho no campo, é preciso encontrar brechas para propor - e sempre de forma flexível - possíveis procedimentos de ação, respaldados nos saberes que o grupo dispõe. Na escola campo desse estudo, para articular o projeto de intervenção pautado na pesquisa e voltado para as necessidades docentes e discentes, os participantes tiveram que abrir espaços para refletir sobre os problemas identificados no cotidiano. Isso, que parece tão simples, é algo muito difícil de ser alcançado pela falta de disponibilidade de horário do professor, cujo tempo se encontra quase todo preenchido pelas atividades de sala de aula. Um outro problema foi (re)definir os conceitos teóricos e metodológicos que embasavam os procedimentos didático-pedagógicos das professoras. Muitas horas de estudos e muitas discussões foram bem gastas procurando alcançar a mediação teórica necessária. De igual modo, coube refletir sobre as concepções de aluno, de ensino, de aprendizagem e de alfabetização. Por meio desse embate teórico-prático foi sendo consolidada a noção de que todas as crianças têm potencial para aprender a ler e a escrever e de que o ensino deve ser contextualizado, situando os usos e funções da língua e valorizando as experiências socioculturais. $\mathrm{Na}$ prática, isso significou abandonar a visão reducionista que valorizava 
somente a habilidade de codificar e decodificar os sinais do sistema de escrita, no período de alfabetização. A complexidade do aprender a ler e escrever foi ficando patente.

Analisar a avaliação diagnóstica e processual, evidenciando as potencialidades e capacidades dos alunos e não suas supostas dificuldades, foi algo bastante complexo. Foi necessário mudar o foco da avaliação, enfatizando mais o produto do que o processo. Isso requereu das professoras deste estudo uma ressignificação de seus critérios avaliativos, passando a considerar como fonte de problemas os fatores internos à sala de aula. Surgiram, assim, alternativas menos dogmáticas sobre o desenvolvimento escolar. Os resultados obtidos perderam o caráter de julgamento definitivo e passaram a respaldar novas possibilidades de intervenção, marcando a necessidade de (re)planejamento embasado nos resultados da avaliação e no desenvolvimento dos alunos em suas atividades diárias. Dessa forma, os saberes discentes tornaram-se pontos de partida para a produção de novos conhecimentos, o que implicou (re)construção de práticas pedagógicas com base no nível de conhecimento dos alunos, no tempo e nos recursos disponíveis, no domínio do professor em relação ao conteúdo etc.

Pela falta de hábito da escola de recorrer à pesquisa para compreender e propor soluções aos problemas cotidianos e por aguardar respostas prontas às demandas existentes, constituiu uma aprendizagem importante saber levar adiante ações de natureza coletiva. Havia nessa instituição uma grande expectativa de que um projeto externo fosse nela desenvolvido, atendendo suas necessidades e eliminando seus problemas. Sendo assim, a escola não se percebia como produtora de saber e esperava que a pesquisa apresentasse a solução. Para desfazer esse equívoco e propor uma intervenção resultante de reflexões coletivas, foi preciso passar por um momento de "desencanto", quando houve a compreensão de que as propostas, se não forem feitas com os participantes, estão fadadas ao fracasso. Propostas feitas para os participantes não dão certo porque alijam os conhecimentos e experiências docentes, porque não os envolve na produção do sucesso. Mas é difícil deixar de acreditar em mágicas e perceber que só por meio de estudos e análises dos casos de alunos com problemas de aprendizagem é possível buscar formas mais coerentes para a práxis pedagógica, abandonando justificativas externas que localizam 
nos alunos e em suas famílias os grandes culpados pelo "fracasso escolar". Pode-se afirmar que a formação continuada é um caminho sólido para a produção do conhecimento, sempre que permitir ao educador articular ações para lidar com os alunos, contribuindo para amenizar a repetência e a evasão. Gradativamente, vem a compreensão de que não há respostas prontas ou métodos pré-definidos e de que é a realidade da instituição que define as possibilidades de se oferecer um ensino de boa qualidade para todos os alunos. Faz-se necessário, porém, ânimo para desestabilizar crenças e dogmas, segundo os quais "nada pode ser feito". De fato, é somente a lida com esses conflitos que torna os educadores agentes de mudança e proponentes de novas e melhores perspectivas educacionais.

O enfrentamento desses problemas no campo, junto com os participantes da pesquisa, revelou que uma ação contrária à ordem estabelecida resulta sempre em dificuldades a serem superadas e, consequentemente, em crescimento e amadurecimento do grupo. $\mathrm{O}$ pesquisador, envolvido de forma emocional, racional e imaginativa, deve se conter para não se impor e respeitar a realidade de cada participante, professoras ou aluno. Da mesma forma, não é possível controlar as dimensões das mudanças ocorridas no campo, posto que elas se relacionam ao contexto e ao momento histórico. Se é verdade que se espera que problemas sejam resolvidos por meio da pesquisa de intervenção, deve-se ter claro, também, que as soluções trazem outras questões, as quais exigem novos passos e assim continua-se a trajetória, imprevisível, desconhecida e desafiadora de modificar as práticas de alfabetização. Uma trajetória que é tudo isso, mas, contraditoriamente, não se faz sem dor, nem sem medos, nem sem angústia. Enfrentar o novo é, de fato, algo muito difícil.

\section{Referências}

ALVARENGA, Daniel. Análise de Variações Ortográficas. Revista Presença Pedagógica. Belo Horizonte, v. 2, n.2, ano 1, p. 24-35, mar./abr. 1995.

BECKER, Fernando. A Origem do Conhecimento e a Aprendizagem Escolar. Porto Alegre: Artmed, 2003. 
LIMA, Lauro Oliveira de. Piaget - Sugestões aos Educadores. 2. ed. Petrópolis: Vozes, 2000.

MIRANDA, Maria Irene. Crianças com Problemas de Aprendizagem na Alfabetização - Contribuições da teoria piagetiana. Araraquara: J.M. Editora, 2000.

PIAGET, Jean. Psicologia e Pedagogia. Rio de Janeiro: Forense, 1969.

THIOLLENT, Michel. Metodologia da Pesquisa-ação. 6. ed. São Paulo: Cortez, 1994.

VINH-BANG. A intervenção psicopedagógica. In: . Archives de Psychologie. Paris, v. 58, n. 225, p. 123-35, 1990. 